\title{
Editorial
}

\section{VIOLENCIA CONTRA LA MUJ ER EN CHILE: PROBLEMA DE SALUD PÚBLICA}

Al momento de escribir este editorial el Servicio Nacional de la Mujer (SERNAM) registra en Chile 48 muertes de mujeres a manos de sus parejas en el año en curso (1). El 9 de junio de 1994, la Organización de Estados Americanos, en la Convención Interamericana para Prevenir, Sancionar y Erradicar la Violencia contra la Mujer "Convención de Belem do Pará", estableció como violencia contra la mujer: Cualquier acción o conducta, basada en su género, que cause muerte, daño o sufrimiento físico, sexual o psicológico a la mujer, tanto en el ámbito público como en el privado. Que tenga lugar dentro de la familia 0 unidad doméstica o en cualquier otra relación interpersonal, ya sea que el agresor comparta o haya compartido el mismo domicilio de la mujer, y que comprende, entre otros, violación, maltrato y abuso sexual; o que tenga lugar en la comunidad $y$ sea perpetrada por cualquier persona y que comprende, entre otros, violación, abuso sexual, tortura, trata de personas, prostitución forzada, secuestro y acoso sexual en el lugar de trabajo, así como en instituciones educativas, establecimientos de salud o cualquier otro lugar, y que sea perpetrada o tolerada por el Estado o sus agentes, donde quiera que ocurra (2).

Como consecuencia de eso y otras iniciativas del Estado de Chile, el 29 de agosto de 1994 se promulgó la ley 19.325 de Violencia Intrafamiliar, y en 1996 se ratificó lo establecido en la Convención de Belem do Pará. El 7 de octubre de 2005 la ley 20.066 sustituye la anterior y modifica el Código Penal (3). Esta nueva ley viene a corregir falencias de la anterior y establece el deber del Estado de adoptar políticas orientadas a prevenir la violencia intrafamiliar y a prestar protección a las víctimas, especialmente a la mujer y los niños, como también amplía el espectro de las víctimas, elimina la calificación de lesiones leves, eleva las penas, mejora las medidas de protección a las víctimas, aumenta las atribuciones de Carabineros de Chile, configura un nuevo delito denominado "maltrato habitual" y establece en el SERNAM proponer las políticas públicas para el cumplimiento de los objetivos establecidos en la nueva ley.

Un estudio multipaís realizado por la OMS en 2005 , estableció que entre el 15 y $71 \%$ de las mujeres que había tenido pareja alguna vez, había sufrido violencia física o sexual o ambas, a lo largo de su vida, por parte de su pareja (5). En ese mismo estudio, las mujeres que fueron objeto de violencia durante el embarazo osciló entre el $1-28 \%$, y el $25-50 \%$ de ellas recibió patadas y puñetazos en el abdomen (5).

¿Qué sucede en Chile? En 2001, SERNAM informa que $50,3 \%$ de las mujeres casadas o en uniones de hecho, ha vivido alguna vez situaciones de violencia de parte de la pareja; $34 \%$ ha vivido violencia física o sexual; $16,3 \%$ abuso psicológico; $42,7 \%$ ha sufrido violencia sexual antes de los 15 años; $22 \%$ señala amenazas con armas; $33 \%$ ha sido víctima de violencia sexual luego de violencia física; $88 \%$ confirma que el agresor es la pareja; la denuncia se establece con un promedio de 7 años de abuso y violencia; $60 \%$ de las mujeres son pobres y $38 \%$ pertenecen a estrato alto y medio alto (6). En 2005, la tasa de denuncias por abusos y violaciones en mujeres adolescentes entre 14-19 años fue de 185,9/100.000 mujeres de esa edad, 394 denuncias por violación y 944 por abusos; en menores de 14 años hubo 263 denuncias por violación y 1.085 por abusos, significativamente mayores a lo ocurrido en 2004; la tasa de denuncias por violencia fue 129/10.000 
mujeres $\geq 15$ años, el $81,8 \%$ tiene entre $20-64$ años y 13,8\% entre 10-19 años (7). En 2006 hubo 35 muertes de mujeres por violencia de género y al 29 de septiembre del año en curso 48 muertes, pese a la vigencia de la ley 20.066.

Estas cifras no nos enorgullece como país, la violencia contra la mujer pasa a ser un severo problema de salud pública, que produce mayor morbilidad y mortalidad que la provocada por el embarazo, parto y puerperio (8) y la Sociedad Chilena de Obstetricia y Ginecología, cuyo principal objetivo es la salud integral de la mujer, no solamente debe colaborar con instituciones preocupadas de este importante tema, sino que liderarlas.

\section{Dr. EnRIQUe Donoso Siña Editor Jefe Revista Chilena de Obstetricia y Ginecología}

\section{REFERENCIAS}

1. Servicio Nacional de la Mujer. 48 femicidios en lo que va corrido del año. Hallado en: http://www.sernam.cl/ publico/noticia.php?not=695. Acceso: 29 de septiembre de 2007.

2. Organización de Estados Americanos. Convención de Belem do Pará. Hallado en: http://www.acnur.org/ biblioteca/pdf/0029.pdf. Acceso: 29 de septiembre de 2007.

3. Ministerio de Justicia de Chile. Ley 20.066 de violencia intrafamiliar. Hallado en: http://www.bcn.cl/leyes/ pdf/actualizado/242648.pdf. Acceso: 29 de septiembre de 2007.

4. Gobierno de Chile, Servicio Nacional de la Mujer. Evaluación de la implementación de las disposicio- nes de la Convención Interamericana para prevenir, sancionar y erradicar la violencia contra la mujer, Convención de Belem do Pará. Hallado en: http:// www.sernam.cl/admin/docdescargas/seccion/ categorias/subcategorias/subcat_180.pdf. Acceso: 29 de septiembre de 2007.

5. Organización Mundial de la Salud. Estudio multipaís de la OMS sobre salud de la mujer y violencia doméstica contra la mujer: primeros resultados sobre prevalencia, eventos relativos a la salud y respuestas de las mujeres a dicha violencia. Hallado en: http://www.who.int/gender/violence/who_ multicountry_study/summary_report/summary reportSpanishlow.pdf. Acceso: 29 de septiembre de 2007.

6. Centro de Estudios de la Mujer, Centro de Estudios para el Desarrollo de la Mujer, Comité de América Latina y del Caribe para la Defensa de los Derechos de la Mujer, Corporación de Desarrollo de la Mujer La Morada, Corporación DOMOS, Corporación Humanas, Facultad Latinoamericana de Ciencias Sociales, Foro-Red de Salud y Derechos Sexuales y Reproductivos-Chile, Instituto de la Mujer, Movimiento pro-emancipación de la Mujer Chilena. Informe Sombra CEDAW, Chile 2003-2006. Hallado en: http:/ /www.anuariocdh.uchile.cl/anuario03/Documentos Relacionados/Seccion_\%20Nacionall_ MedinaQuiroga/InformeSombraalCuartolnformeChile.pdf. Acceso: 29 de septiembre de 2007.

7. Organización Panamericana de la Salud. Respuestas efectivas en violencia de género: materias pendientes. Observatorio de equidad de género en salud. Informe 2006. Hallado en:

http://www.observatoriogenerosalud.cl/Documentos/ Respuestas_Efectivas_en_Violencia_de_Genero.pdf. Acceso: 29 de septiembre de 2007.

8. Donoso E. Mortalidad Materna en Chile, 2000-2004. Rev Chil Obstet Ginecol 2006;71(4):246-51. 